\title{
Study on the Prediction of the Height of Two Zones in the Overlying Strata under a Strong Shock
}

\author{
Xingping Lai $\mathbb{D}^{1,2}$, Bowei Liu $\mathbb{D}^{1},{ }^{1}$ Pengfei Shan $\mathbb{D}^{1,2}$ Feng Cui, ${ }^{1,2}$ Yun Zhang, ${ }^{1,2}$ \\ Xudong Zhang, ${ }^{1}$ Rui Bai, ${ }^{1}$ and $\mathrm{Xuan} \mathrm{Wu}^{3}$ \\ ${ }^{1}$ School of Energy Engineering, Xi'an University of Science and Technology, Xi'an 710054, China \\ ${ }^{2}$ Key Laboratory of Western Mines and Hazard Prevention, Ministry of Education, Xi'an 710054, China \\ ${ }^{3}$ China-ASEAN Geosciences Cooperation Center (Nanning), Nanning, Guangxi 530023, China
}

Correspondence should be addressed to Pengfei Shan; shanpengfei@xust.edu.cn

Received 22 April 2021; Accepted 14 August 2021; Published 7 September 2021

Academic Editor: Yi Xue

Copyright ( 2021 Xingping Lai et al. This is an open access article distributed under the Creative Commons Attribution License, which permits unrestricted use, distribution, and reproduction in any medium, provided the original work is properly cited.

\begin{abstract}
A development of overlying strata fractures and an unknown distribution of the two zones, which results from a strong shock tendency roof short-distance coal seam group mining, are the main problems faced by Xiashijie Coal Mine. Consequently, an experiment has been conducted; here are the steps: designing an underlying strata development law and the two-zone distribution physical similarity simulation test under the short-distance coal seam group combined mining, using the BT-AE to comonitor the fracture development law and the distribution characteristics of the caving zone and the water-conducting fractured zone, and combining with 3DEC comparative analysis. The results show that after the coal seam mining is over, the number of overlying fractures increases with depth, controlled by the mining stress field in the direction of $115^{\circ}$ west from north to west. The direction of overlying fracture is mainly concentrated in the area of $300^{\circ} \sim 30^{\circ}$; the overlying fracture angles eventually develop to $81^{\circ}$ and $74^{\circ}$, increasing by $15.7 \%$ and $8.8 \%$, and the caving ratio and cracking ratio are 4.87 and 17.75 . After comparing with the numerical calculation results, the reliability of the two zones obtained by the physical similarity simulation test is verified. The $\mathrm{AE}$ analysis results show that the "release-accumulate-release" energy evolution process of overlying rock fracture under mining conditions has a phased relationship with fracture expansion. The energy positioning results are consistent with the distribution of BT observation cracks, and the large energy events are mostly concentrated in the collapse zone, indicating that $\mathrm{AE}$ has the practicality of disaster warning. The results of this study provide scientific guidance for water-preserving mining under the combined mining of coal seams with a strong impact tendency roof in Xiashijie Coal Mine.
\end{abstract}

\section{Introduction}

As an important industrial raw material in China, coal resources will not change their dominant position for a long time. Xie et al. [1] proposed that China's total energy consumption demand in 2025 will be 5.5 to 5.6 billion tons of standard coal, accounting for $50 \%$ to $52 \%$ of full energy consumption. However, the mining of coal will inevitably cause the movement and fracture of the overlying strata and the formation of cracks at the same time. The existence of fissures will cause the overlying aquifer to seep to the working face and cause underground water inrush accidents. While water resources are wasted, it also brings major hidden dangers to underground safety production. Therefore, it is very necessary to study the development law of overlying fractures and the distribution patterns of the two zones after mining in a fully mechanized caving face.

Many scholars at home and abroad have made relatively mature researches in theory and practical applications for the evolution of overlying fractures and water conservation mining. Fan [2] puts forward some suggestions on waterpreserving coal mining based on the perspective of scientific development. Wang et al. [3] proposed the characteristics of overburden failure and deformation caused by highintensity mining and its impact on the environment and at the same time gave a formula for calculating the height of the "two zones" under high-intensity mining. Zhao et al. [4] suppressed the contact between the height of the water- 
conducting fissure zone and the strong aquifer of the overburdened rock to control the problem of water gushing in the overlying rock. Lai et al. [5] obtained the overlying rock migration damage height of fully mechanized caving face through physical similarity simulation research and determined the relationship between the measured resistance of the on-site support and the water conduction position and the amount of water conduction in the overlying rock fracture. Wang et al. [6] used the entropy method-cloud model to evaluate the ecological environment of certain mining areas that are mainly based on water conservation mining. Wang et al. [7] analyzed the positional relationship between coal seams and aquifers through the combination of indoor experiment and field and proposed to partition the stability of the mining water barrier and standardize the coalmining method, in order to carry out scientific mining in mining areas with fragile ecological environment. Guo et al. [8] obtained the formation mechanism of the "twozone" failure mode of overlying strata in high-strength mining by studying the failure transmission process of overlying strata. Cheng et al. and Xue et al. $[9,10]$ studied the evolution characteristics of the overburden fissure zone caused by the mining disturbance in the soft rock protection layer. Research by Yang et al. [11] showed that the waterconducting fracture zone under thick loose layer and weak overburden will go through four stages, and it will develop upward in the form of separation layer, mostly in the form of articulation. Wang et al. [12] found that through theoretical analysis and on-site detection and analysis that the height of the water-conducting fracture zone is affected by the thickness of the coal seam and the structure of key layers, and the height changes stepwise with the thickness of the coal seam. Zhao et al. [13] found that the height of the water-conducting fracture zone is affected by the thickness of the mining, the thickness of the bedrock, and the thickness of the load layer. Liu and Zhao [14] analyzed and verified the protective mechanism and effect of coal filling mining on the roof aquifer by constructing a mechanical model and similar simulation tests. Huang et al. [15] combined numerical calculation model with physical simulation and theoretical analysis and concluded that the evolution of overlying strata cracks is affected by the distance between coal pillars in different sections. Yang et al. [16] obtained the smallest safe waterproof coal pillar size through RFPA2D analysis. Fan and Liu [17] observed and analyzed the leakage vector of flushing fluid in downhole boreholes and the development of cracks in the hole wall and found that mining cracks showed a dynamic evolution characteristic of "generation-development-bridging." Wu et al. [18] quantitatively evaluated the mining disturbance area through observation of borehole images. Dong et al. [19] proposed a new technology for the protection of burnt rock water and its impact on coal mining. Guo and Dong [20] established a numerical model of groundwater seepage and studied the seepage laws of different aquifers affected by the fracture zone. Du et al. [21] proposed the principle of direct roof control for coal mining with strip structure filling "water retention-storage." Lai et al. [22-25] observed, analyzed, and determined the height and spatial distribution of the water-conducting fissure zone in the internal subsidence zone, and the fracture zone after the coal seam was excavated.

The abovementioned researches have made useful explorations on the evolution of fractures and the distribution of the two zones in my country's coal mine water conservation mining and laid a solid foundation for subsequent researches. In this paper, aiming at the joint mining of close-range coal seams with a strong impact tendency in Xiashijie Coal Mine, the method of physical similarity simulation test is used, the law of crack development and the distribution of the two zones are obtained through the drilling $\mathrm{TV}$ and acoustic emission monitoring system and establish a 3DEC numerical calculation model to verify it and provide a scientific basis for the safe production of Xiashijie Coal Mine and the protection of water resources.

\section{Engineering Background}

2.1. Geological Structure Characteristics and Coal Seam Occurrence in Xiashijie Coal Mine. Xiashijie Coal Mine is located in the northwest of Tongchuan City, Shaanxi Province. The mine field is $4 \mathrm{~km}$ long, with a slope of about $3.3 \mathrm{~km}$ wide and a coal-bearing area of $13.2 \mathrm{~km}^{2}$. The mine has 127 million tons of recoverable reserves, and the original design service life is 101 years. The buried depth of the coal seam is $640 \mathrm{~m}$, and the roof of the coal seam tends to impact. The bedding and fissures of the 3-2\# coal seam are relatively developed, and the hardness of the 3-2\# coal seam is medium. The first mining face is 2301 working face, the slope length is $210 \mathrm{~m}$, and the mining thickness is $4.5 \mathrm{~m}$. The 4-2\# coal seam is relatively stable, with developed endogenous fissures, flakes, and collapses. The first mining face is 222 with an oblique length of $210 \mathrm{~m}$ and a mining thickness of $10.0 \mathrm{~m}$.

2.2. Coal Roof and Floor Characteristics. The 3-2\# coal seam is directly topped by dark-gray silty mudstone and siltstone, the rock layer is relatively broken, and the average thickness is $2.0 \mathrm{~m}$. The $3-2 \#$ coal seam floor is gray to dark-gray siltstone, commonly known as black sandstone, with an average of $7.35 \mathrm{~m}$.

The direct roof of 4-2\# coal seam is dark gray-gray black siltstone, thin-layered, partially sandy mudstone and mudstone, and argillaceous cement. 4-2\# coal seam floor is carbonaceous mudstone, black, thin-layered, and with an average thickness of $6.16 \mathrm{~m}$. The mean distance between 32 \# coal seam and $4-2$ \# coal seam is $21.76 \mathrm{~m}$.

2.3. Mine Hydrological Characteristics. The surface of the mine is mostly covered by vegetation, with dense forests and vertical and horizontal valleys. There are no rivers and other water bodies. Due to the high terrain, there will be no water accumulation in the rainy season. Since the distance between 3-2\# coal seam and 4-2\# coal seam is $21.76 \mathrm{~m}$, the water inflow of 3-2\# coal seam is the same as that of 4-2\# coal seam. In the mining of 3-2\# coal seam, the normal water inflow of the mine is $100 \sim 120 \mathrm{~m}^{3} / \mathrm{h}$, and the maximum water inflow is $170 \mathrm{~m}^{3} / \mathrm{h}$. 
According to the analysis of mine hydrogeological data, during the mining process of 222 working face, some sections of the water-conducting fracture zone will directly affect the Luohe Formation, and some sections of the Luohe Formation aquifer water indirectly enter the underground through the Yijun Formation. After the upper 2301 working face was mined, the structure of the overlying water-bearing (impermeable) layer was destroyed, and water in the goaf poured into the 222 working face. According to the "Mine Geological Report" (revised), it is estimated that the normal water inflow of 222 working face is $42.6 \mathrm{~m}^{3} / \mathrm{h}$, and the maximum water inflow is $223.7 \mathrm{~m}^{3} / \mathrm{h}$.

\section{Experimental Study on the Development of Mining Overlying Strata and the Distribution of Two Zones}

3.1. Physical Model Design. The Xiashijie Coal Mine was used as the experimental research object, and threedimensional models with length, width, and height of $3.0 \mathrm{~m}, 0.2 \mathrm{~m}$, and $1.7 \mathrm{~m}$ were selected. According to the similarity theory, the geometric similarity ratio is selected as $1: 400$, the stress similarity ratio is $1: 600$, and the pressure similarity ratio is $1: 1.2 \times 10^{7}$. The similar materials required for the test are mainly sand, white powder, plaster of paris, mica, and water, among which fly ash is added when the coal seam is proportioned, and the mica powder is used for layering. According to the corresponding ratio, mix and stir evenly and then pave it on the model frame to simulate the process of deformation and collapse of different rock layers during the mining process. The physical and mechanical parameters and material loading ratio of coalmeasure formation are shown in Table 1.

3.2. Test and Equipment Monitoring Program. There are $20 \mathrm{~cm}$ boundary coal pillars on both sides of the model. The working face advances from left to right, and a total of $260 \mathrm{~cm}$ is excavated. The experiment first simulates mining 3-2\# coal seam, with a $1.5 \mathrm{~cm}$ stop for a total of 187 times. After the 3-2\# coal seam is mined, 4-2\# coal seam is mined with a $1.0 \mathrm{~cm}$ stop for a total of 260 times.

Two peepholes with the same diameter of $60 \mathrm{~mm}$ and depth of $150 \mathrm{~cm}$ are evenly arranged along with the model frame. The number from left to right is $1 \#$ drilling and 2\# drilling, and the distance between the two drillings is $96 \mathrm{~cm}$. When the overburden is destroyed by pressure, the GD3Q-GA drilling TV is used to observe the full-hole $360^{\circ}$ through the peephole, and the collected images are processed to obtain a plane expansion map to observe the changes of the overburden. At the same time, the cracks in the stage can be fitted, the azimuth angle can be measured, and the number of cracks and the change law of azimuth can be obtained by analysis. The model test system is shown in Figure 1.

At the beginning of the test, the Express- 8 acoustic emission system developed by the American company Mistral was used to monitor the amount of energy released during the overburden failure, the change in the severity of the damage, and the location of the event in real-time. By mon- itoring and analyzing the acoustic emission signal during the mining process of the working face, it can reflect the overburden failure, fracture, and the distribution law of the two zones during the mining process of the model working face.

\section{Analysis of the Development of Cracks in the Overlying Rock and the Characteristics of the Two Zones}

\subsection{The Development Number and Direction Characteristics} of Overlying Rock Fractures. The number of fractures in the overlying rock can objectively reflect the damage degree of the rock mass affected by mining disturbance. In this test, based on the structural plane joints measured by the borehole TV, a set of data for every $10 \mathrm{~cm}$ of the borehole depth is used to draw a figure of the number of cracks in the overburden rock in boreholes 1\# and 2\# after the mining of the two working faces and compare the two, as shown in Figure 2. After the end of mining in the 2301 working face and the 222 working face, due to the support of the main key layer, the number of cracks in the range of $1 \#$ drilling depth $60 \mathrm{~cm} \sim 70 \mathrm{~cm}$ and 2\# drilling $70 \mathrm{~cm} \sim 80 \mathrm{~cm}$ is significantly less than the number of cracks in the upper and lower sections.

It can be seen from Figure 2 that after the rock formation is affected by mining disturbance, the number of fractures below the main key layer is more than the number of cracks above, and the number of overburdened fractures increases with the increase of drilling depth. That is to say, the roof overlying rock above the working face is damaged by mining disturbance, and there are many cracks.

The azimuth rose diagram of the model overlying cracks monitored by the borehole TV is shown in Figure 3. In the range of $0^{\circ} \sim 360^{\circ}$, the fissures in different orientations of the $1 \#$ and $2 \#$ boreholes in the two working faces are drawn for each $10^{\circ}$ as a group. In Figure 3(a), after the end of the mining in the 2301 working face, the 1 \# borehole has $1 \mathrm{crack}$ at $160^{\circ}, 2$ cracks in the range of $292.5^{\circ} \sim 315^{\circ}, 1$ crack at $335^{\circ}$, and 3 cracks in the range of $337.5^{\circ} \sim 360^{\circ}$; the remaining fissures are between $22.5^{\circ}$ and $90^{\circ}$, of which there are 8 fissures in the range of $40^{\circ}$ to $45^{\circ}$. In Figure $3(\mathrm{~b})$, after the end of mining in the 2301 working face, the cracks in the $2 \#$ borehole are all distributed in the range of $0^{\circ} \sim 50^{\circ}$. In Figure 3(c), after the end of the mining in the 222 working face, there is 1 fissure at $358^{\circ}$ and 4 fissures at $94^{\circ}$ in No. 1 borehole. The remaining fissures are distributed in the range of $20^{\circ} \sim 90^{\circ}$; there are 12 cracks in the range of $54^{\circ} \sim 58^{\circ}$. Due to the interaction between the rock layers during the mining disturbance, the azimuth of the 1 \# borehole fissure after the end of mining in the 222 working face shifts clockwise from that of the 1\# borehole fissure after the end of the 2301 working face, and the number of deep borehole cracks increased significantly. In Figure 3(d), after the end of the mining in the 222 working face, most of the fractures in borehole 2\# are in the range of $0^{\circ} \sim 90^{\circ}$, and only 7 of the fractures are in the range of $337.5^{\circ} \sim 360^{\circ}$.

It can be seen from Figure 3 that the fissures in boreholes $1 \#$ and $2 \#$ are mainly concentrated in the area of $0^{\circ} \sim 90^{\circ}$, 
TABLe 1: Physical and mechanical parameters of the model and material filling ratio.

\begin{tabular}{|c|c|c|c|c|c|}
\hline \multirow{2}{*}{ Serial number } & \multirow{2}{*}{ Lithology } & \multirow{2}{*}{ Single layer thickness/m } & \multicolumn{3}{|c|}{$1 \mathrm{~cm}$ ingredients } \\
\hline & & & River sand/kg & Plaster/kg & White powder $/ \mathrm{kg}$ \\
\hline 1 & Fine-grained sandstone & 26.00 & 8.40 & 0.36 & 0.84 \\
\hline 2 & Siltstone & 12.30 & 8.40 & 0.24 & 0.96 \\
\hline 3 & Conglomerate & 52.10 & 8.40 & 0.50 & 0.72 \\
\hline 4 & Medium-grained sandstone & 52.80 & 8.40 & 0.48 & 0.72 \\
\hline 5 & Sandstone & 22.02 & 8.40 & 0.50 & 0.72 \\
\hline 6 & Medium-grained sandstone & 28.73 & 8.40 & 0.48 & 0.72 \\
\hline 7 & Sandy mudstone & 33.48 & 8.53 & 0.21 & 0.85 \\
\hline 8 & Coarse-grained sandstone & 14.70 & 8.53 & 0.32 & 0.75 \\
\hline 9 & Sandstone & 23.76 & 8.4 & 0.5 & 0.72 \\
\hline 10 & Medium-grained sandstone & 69.11 & 8.4 & 0.48 & 0.72 \\
\hline 11 & Sandy mudstone & 16.20 & 8.53 & 0.21 & 0.85 \\
\hline 12 & Medium-grained sandstone & 5.00 & 8.4 & 0.48 & 0.72 \\
\hline 13 & Sandstone & 17.80 & 8.4 & 0.5 & 0.72 \\
\hline 14 & Coarse-grained sandstone & 14.60 & 8.53 & 0.32 & 0.75 \\
\hline 15 & Sandy mudstone & 3.90 & 8.53 & 0.21 & 0.85 \\
\hline 16 & Coarse-grained sandstone & 33.00 & 8.53 & 0.32 & 0.74 \\
\hline 17 & Sandstone & 13.50 & 8.4 & 0.5 & 0.72 \\
\hline 18 & Coarse-grained sandstone & 12.88 & 8.53 & 0.32 & 0.74 \\
\hline 19 & Sandy mudstone & 27.18 & 8.53 & 0.21 & 0.85 \\
\hline 20 & Coarse-grained sandstone & 12.90 & 8.53 & 0.32 & 0.75 \\
\hline 21 & Sandy mudstone & 4.62 & 8.53 & 0.21 & 0.85 \\
\hline 22 & Siltstone & 21.47 & 8.4 & 0.24 & 0.96 \\
\hline 23 & Sandy mudstone & 23.03 & 8.53 & 0.21 & 0.85 \\
\hline 24 & Siltstone & 7.36 & 8.4 & 0.24 & 0.96 \\
\hline 25 & Mudstone & 8.74 & 8.53 & 0.21 & 0.85 \\
\hline 26 & Siltstone & 11.02 & 8.4 & 0.24 & 0.96 \\
\hline 27 & Sandstone & 9.07 & 8.4 & 0.5 & 0.72 \\
\hline 28 & Mudstone & 7.07 & 8.53 & 0.21 & 0.85 \\
\hline 29 & Sandstone & 12.16 & 8.4 & 0.5 & 0.72 \\
\hline 30 & Siltstone & 7.24 & 8.4 & 0.24 & 0.96 \\
\hline 31 & $3-2 \#$ coal & 4.50 & 4.15 & 0.21 & 0.42 \\
\hline 32 & Siltstone & 7.21 & 8.4 & 0.24 & 0.96 \\
\hline 33 & Sandstone & 14.55 & 8.4 & 0.5 & 0.72 \\
\hline 34 & $4-2 \#$ coal & 10.00 & 4.15 & 0.21 & 0.42 \\
\hline
\end{tabular}

while the true north direction of the borehole in the model is $60^{\circ}$ west of the actual azimuth. Therefore, the overburden fractures in the mine are mainly distributed in the area of $300^{\circ} \sim 30^{\circ}$, indicating that the development and formation of the fractures in the borehole are mainly controlled by the mining stress field in the direction of $115^{\circ}$ west of the true azimuth.

4.2. Internal Characteristics of Overlying Fractures. Figure 4 shows the imaging and statistical characteristics of the cracks of the overburden in the $1 \#$ borehole at the end of mining the 2301 working face. It can be seen from Figure 4 that within the range of $0 \sim 35.7 \mathrm{~cm}$ of the borehole, mining disturbance has fewer effects on the rock formation in this range, and the rock formation does not appear to sink or cracks. Within the range of $35.7 \mathrm{~cm} \sim 73.4 \mathrm{~cm}$ in the borehole, the rock formation has moved with a little loosening and slagging phenomenon, and the fracture width is about $1.5 \mathrm{~mm}$. Within the range of $73.4 \mathrm{~cm} \sim 114.6 \mathrm{~cm}$ in the borehole, the rock formation forms fissures due to subsidence, but the fissure width is $2 \mathrm{~mm}$. In the range of $114.6 \mathrm{~cm} \sim 150.0 \mathrm{~cm}$ in the borehole, the roof collapsed, the rock formation is more severely damaged, the fracture width was $3 \mathrm{~mm}$, and the crack length showed an overall upward trend with the increase of depth. It can be seen from the borehole TV monitoring that after the end of the mining in the 2301 working face, the height of the collapse zone is $4.9 \mathrm{~cm}$, and the height of the water-conducting fractured zone is $37.4 \mathrm{~cm}$ through the $1 \#$ borehole monitoring. Corresponding to the 2301 


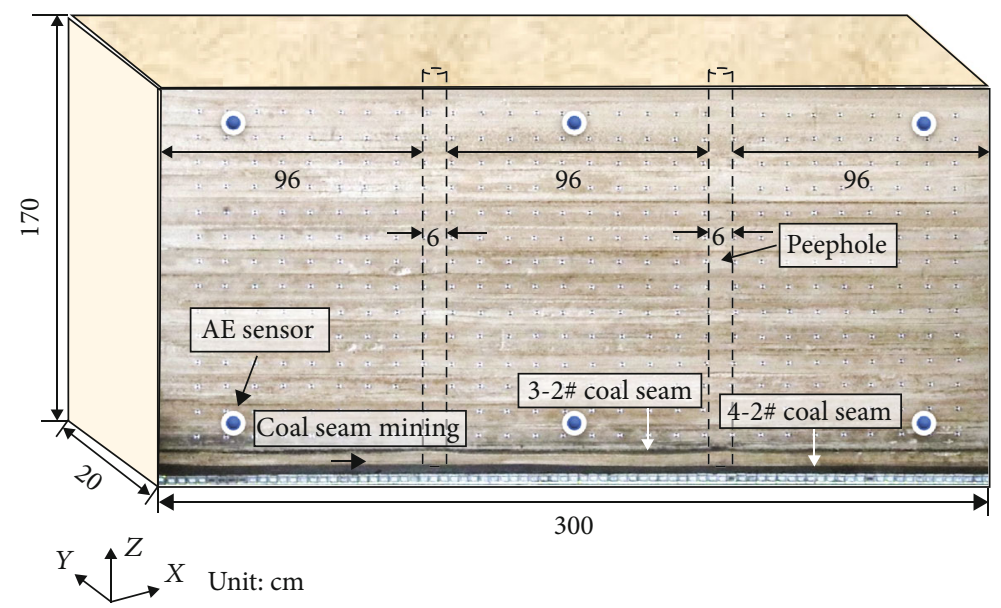

FIgURE 1: Similar material model and equipment layout.

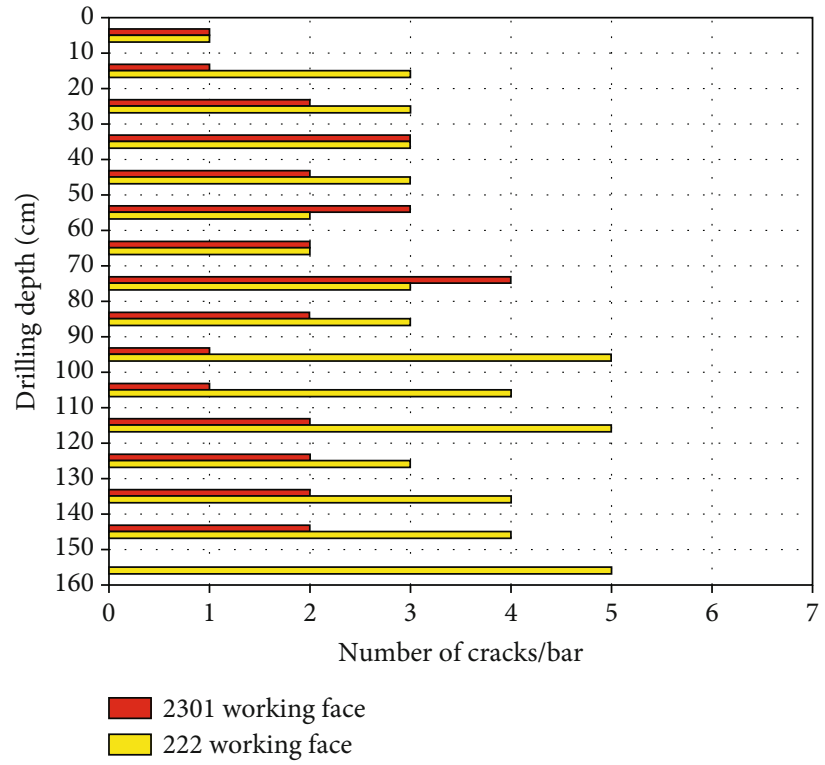

(a) Working face stoping ends 1 \# borehole overlying rock fissure diagram

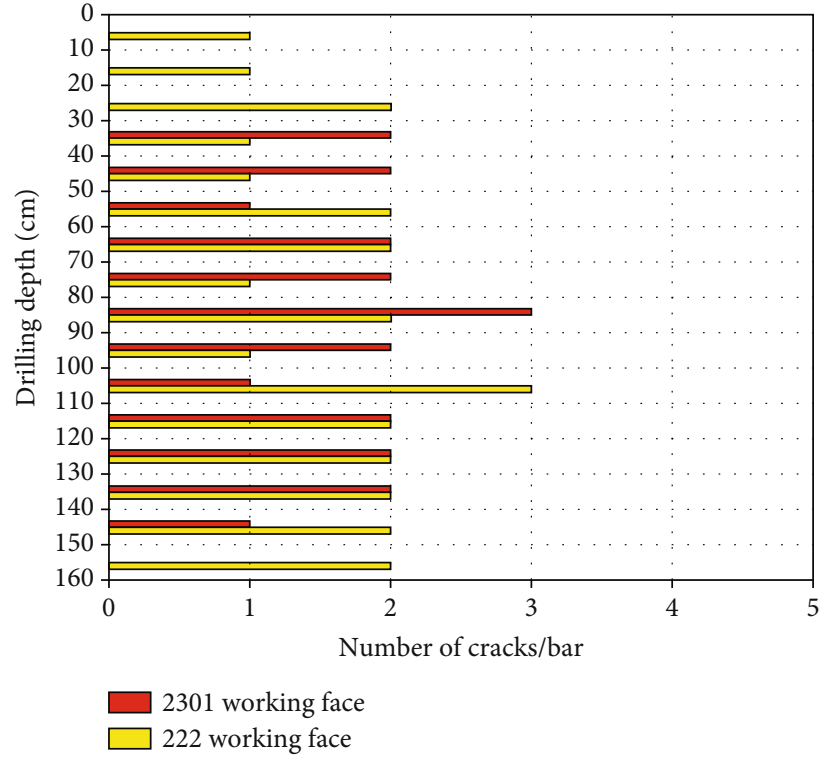

(b) Working face stoping ends $2 \#$ borehole overlying rock fissure diagram

Figure 2: Number of cracks in the overlying rock.

working face of Xiashijie Coal Mine after mining, the rock collapse zone is $19.6 \mathrm{~m}$, and the water-conducting fractured zone is $149.6 \mathrm{~m}$.

Figure 5 shows the imaging and statistical characteristics of the cracks of the overburden in the $2 \#$ borehole at the end of mining the 2301 working face. It can be seen from Figure 5 that within the range of $0 \sim 36.2 \mathrm{~cm}$ of the borehole, mining disturbance has fewer effects on the rock formation in this range, and the rock formation does not sink or crack. Within the range of $36.2 \mathrm{~cm} \sim 74.7 \mathrm{~cm}$ of the borehole, the rock strata have moved, and some loosening and slagging phenomenon occurs. At this time, some cracks with a width of $1 \mathrm{~mm}$ are generated. In the range of $74.7 \mathrm{~cm} \sim 116.8 \mathrm{~cm}$ in the borehole, the rock formations form a narrower and denser circumferential fissure due to subsidence. At the same time, the rock formations in this range are accompanied by shear failure, and longitudinal fissures are generated, and in some areas, the two kinds of fissures are staggered, forming interlaced fissures, and the width of the fissures is $2 \mathrm{~mm}$. In the range of $116.8 \mathrm{~cm} \sim 150.0 \mathrm{~cm}$ of the borehole, the roof collapsed obviously, and the rock strata suffered a tensile failure, and the damage is more serious. Within this range, the average crack width is $2.1 \mathrm{~mm}$. Due to mining disturbances, the rock strata above the working face are seriously damaged, so the width and length of the cracks are larger than the upper strata, and the overall trend is increasing. It can be seen from the borehole TV monitoring that after the end of the mining in the 2301 working face, the height of the collapse zone is $5.2 \mathrm{~cm}$, and the height of the water-conducting fractured zone is $37.6 \mathrm{~cm}$ through the monitoring of the $1 \#$ borehole; corresponding to the 2301 working face of Xiashijie Coal Mine after mining, the rock collapse zone is $20.8 \mathrm{~m}$, and the water-conducting fractured zone is $150.4 \mathrm{~m}$. 


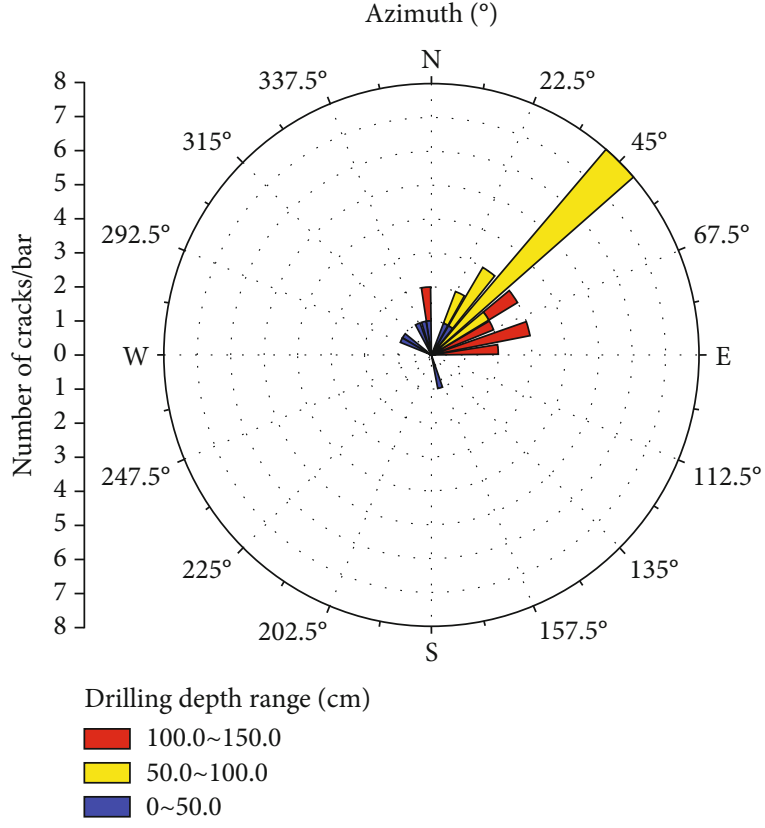

(a) 2301 working face stoping ends 1 \# hole

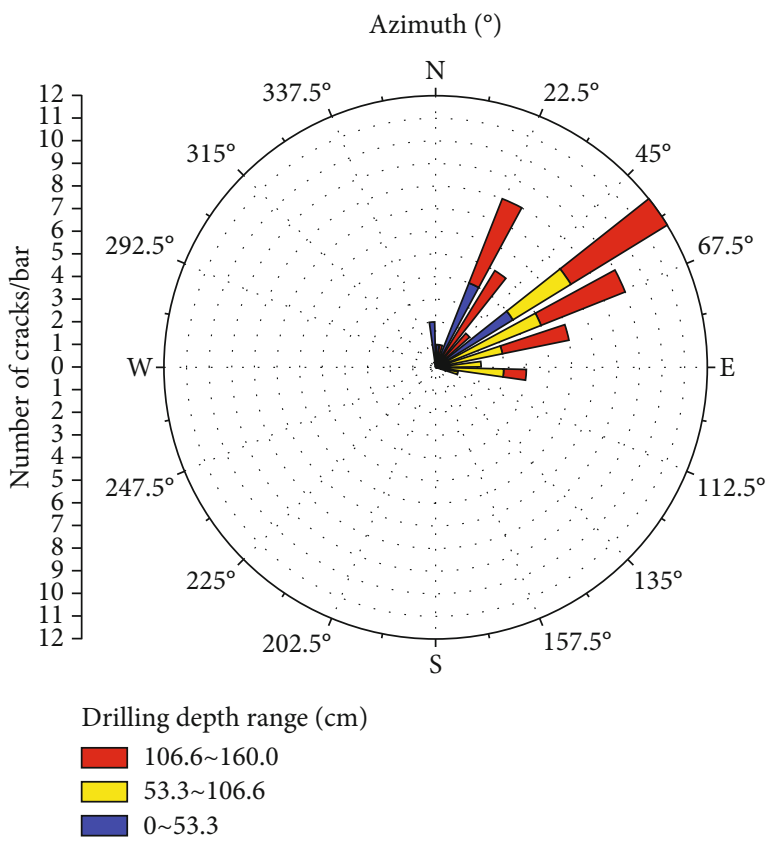

(c) 222 working face stoping ends $1 \#$ hole

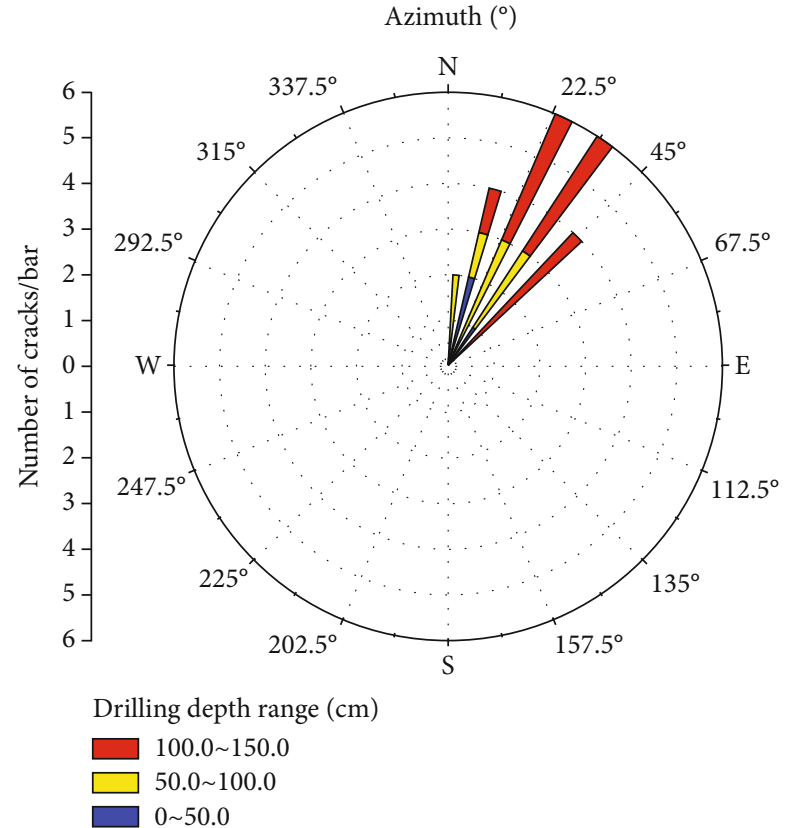

(b) 2301 working face stoping ends 2\# hole

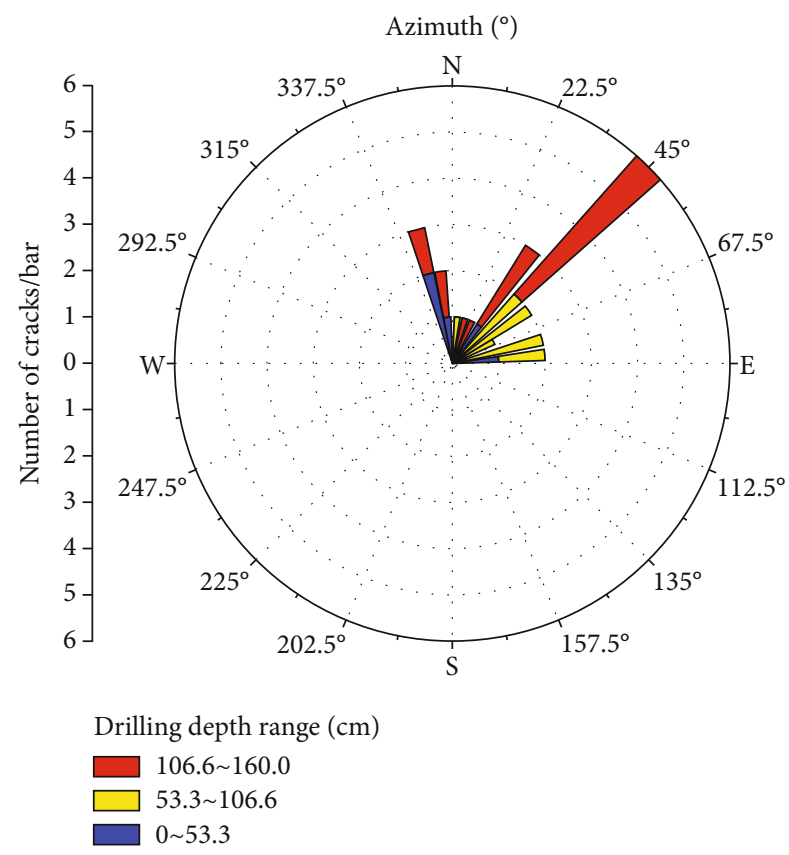

(d) 222 working face stoping ends $2 \#$ hole

Figure 3: Azimuth rose diagram of overlying rock fractures.

Figure 6 shows the imaging and statistical characteristics of the cracks of the overburden in the 1 \# borehole at the end of mining the 222 working face. It can be seen from Figure 6 that within the range of $0 \sim 31.6 \mathrm{~cm}$ in the borehole, the rock strata bend and sink, and the separation layer has developed to the surface, producing small fissures with a width of $1 \mathrm{~mm}$. In the range of $31.6 \mathrm{~cm} \sim 62.7 \mathrm{~cm}$ in the borehole, there are a large number of cracks, and the width of the cracks develops to $2 \mathrm{~mm}$; there is no connection between the rock layers, and this range is at the edge of the bending zone. Within the range of $62.7 \mathrm{~cm} \sim 94.5 \mathrm{~cm}$ in the borehole, the rock formation closed the local fissures due to settlement and its own weight, and the width was reduced to $1 \mathrm{~mm}$. Within the range of $94.5 \mathrm{~cm} \sim 127.5 \mathrm{~cm}$ in the borehole, the lower rock strata are not compacted due to the collapse of the key layer to form a structure, and the crack width is $5 \mathrm{~mm}$. Within the range of $127.5 \mathrm{~cm} \sim 160.0 \mathrm{~cm}$ in the borehole, the roof collapsed obviously, and cracks with a width of $7 \mathrm{~mm}$ and a length of $55 \mathrm{~mm}$ were generated, and the rock formation was seriously damaged. It can be seen from the borehole TV monitoring that after the end of the mining in the 222 working face, the height of the collapse zone is 


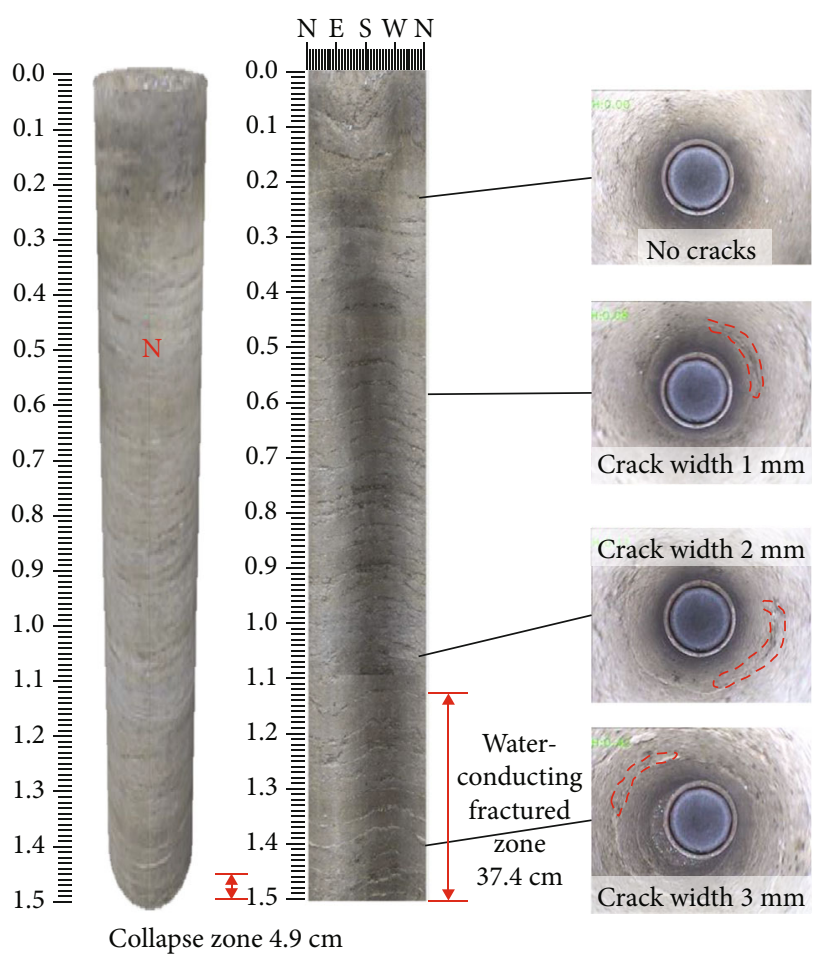

(a) Drilling panoramic fissure peep imaging

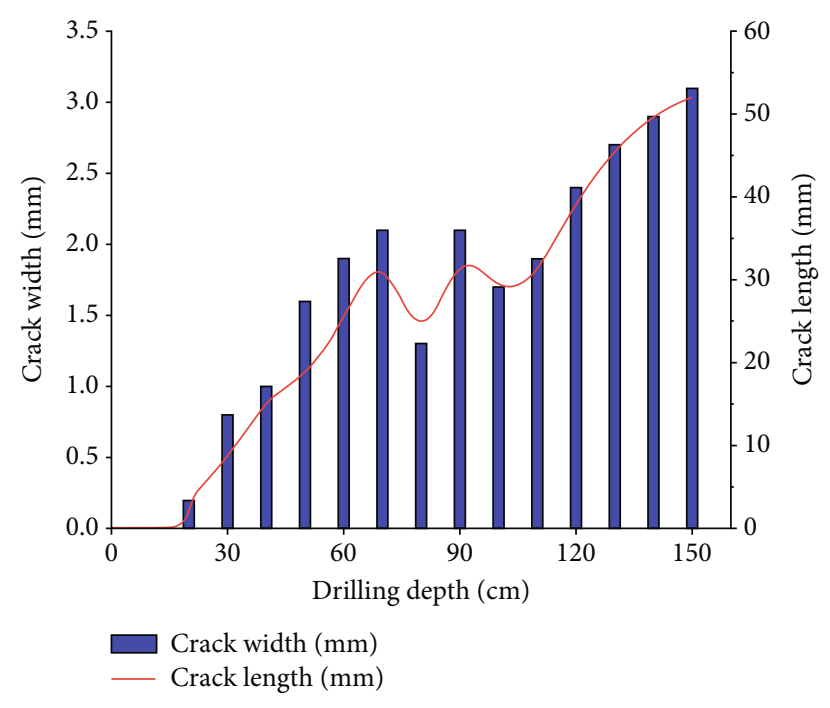

(b) Statistical characteristics of different depth cracks

FIGURE 4: The imaging and statistical characteristics of the overburden cracks in the 1\# borehole after the end of mining the 2301 working face.

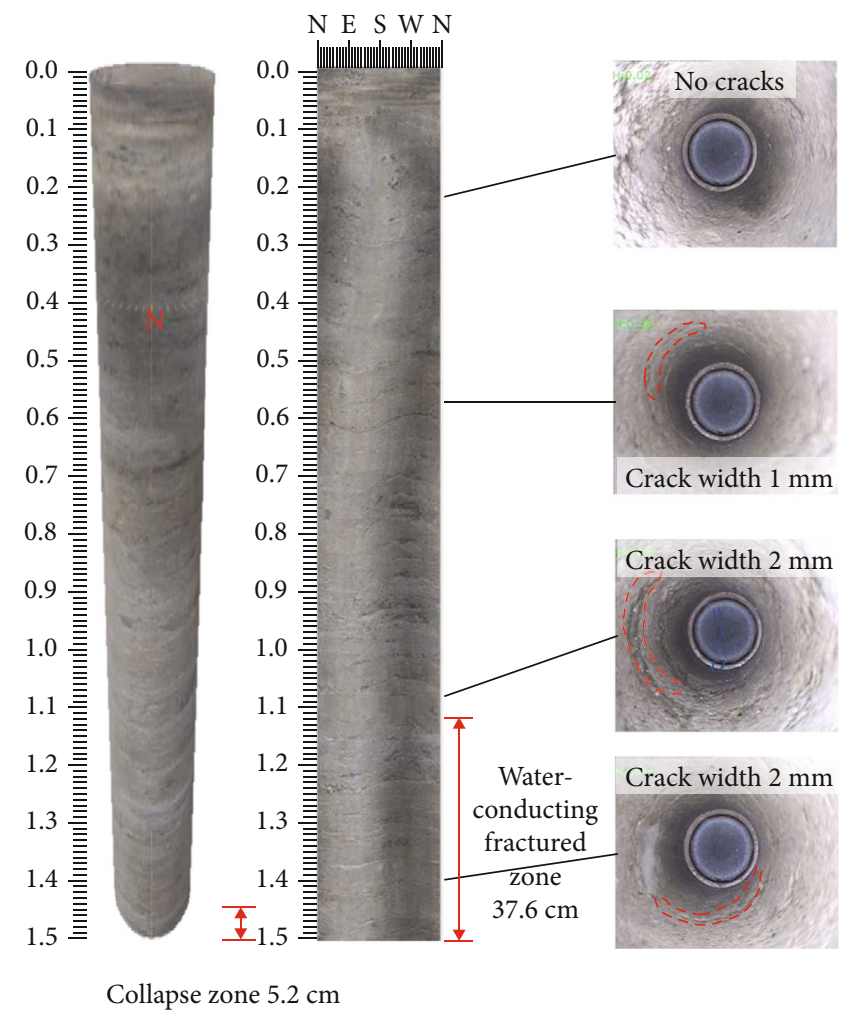

(a) Drilling panoramic fissure peep imaging

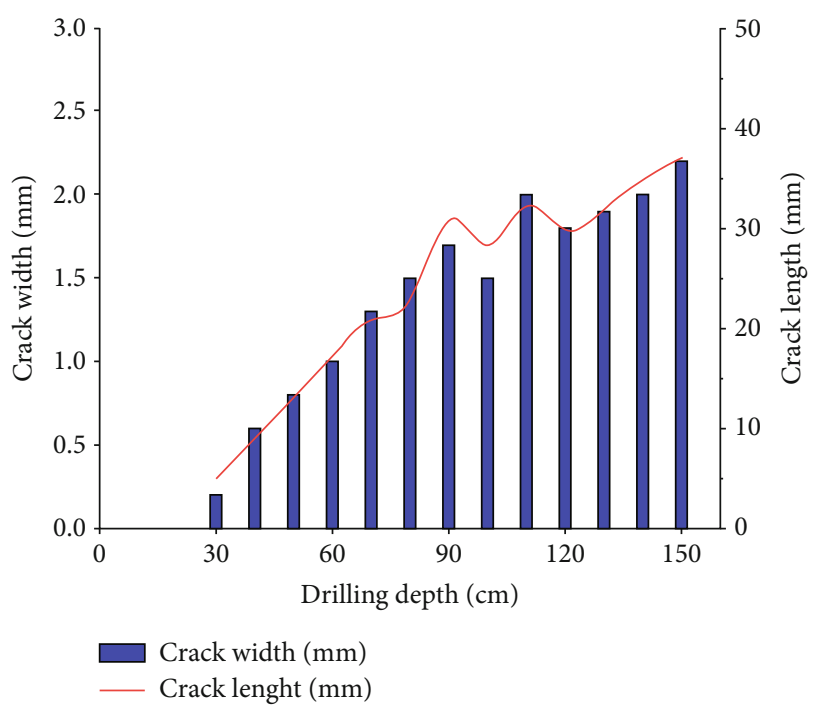

(b) Statistical characteristics of different depth cracks

FIGURE 5: The imaging and statistical characteristics of the overburden cracks in the 2 \# borehole after the end of mining the 2301 working face. 


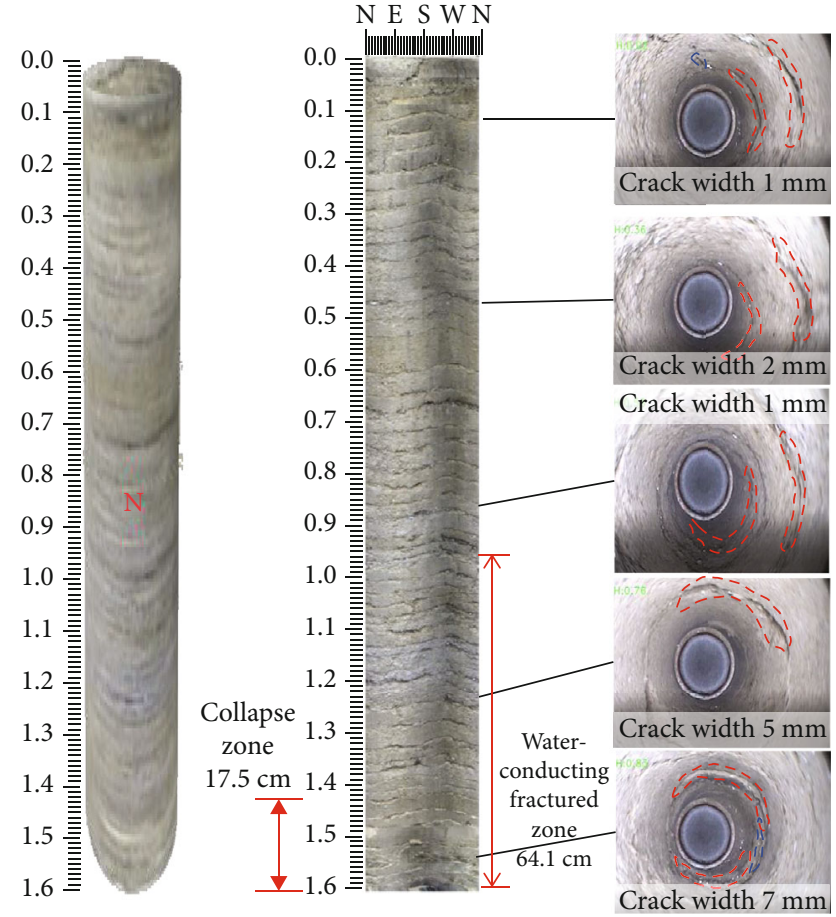

(a) Drilling panoramic fissure peep imaging

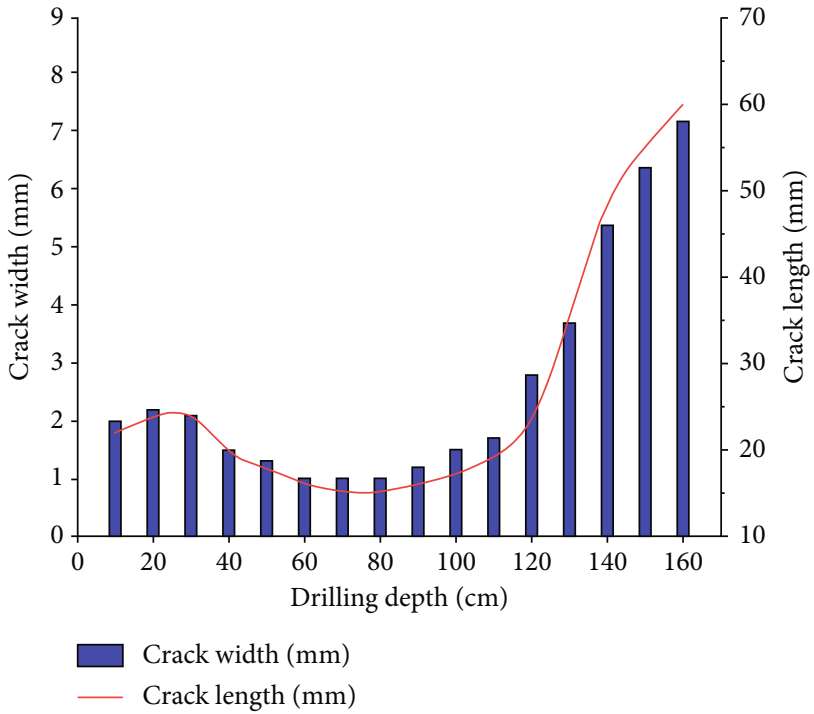

(b) Statistical characteristics of different depth cracks

FIgURE 6: The imaging and statistical characteristics of the overburden cracks in the 1 \# borehole after the end of mining the 222 working face.

$17.5 \mathrm{~cm}$, and the height of the water-conducting fractured zone is $64.1 \mathrm{~cm}$ through the 1 \# borehole monitoring; corresponding to the 222 working face of Xiashijie Coal Mine, the rock collapse zone is $70 \mathrm{~m}$, and the water-conducting fractured zone is $256.4 \mathrm{~m}$.

Figure 7 shows the imaging and statistical characteristics of the cracks of the overburden in the $2 \#$ borehole at the end of mining the 222 working face. It can be seen from Figure 7 that within the range of $0 \sim 40.6 \mathrm{~cm}$ in the borehole, the separation layer has developed to the surface, and the rock formation bends and sinks, resulting in cracks with an average width of $2.2 \mathrm{~mm}$. Within the range of $40.6 \mathrm{~cm} \sim 121.6 \mathrm{~cm}$ in the borehole, local fissures are closed due to rock settlement and self-weight, and the width of the fissures is reduced, with an average value of $1.8 \mathrm{~mm}$. Within the range of $121.6 \mathrm{~cm} \sim 160.0 \mathrm{~cm}$ of the borehole, the roof separation occurred obvious collapse phenomenon, local cracks with a width of $7 \mathrm{~mm}$ and a length of $60 \mathrm{~mm}$ were generated, and within this range, the average crack width was $5.3 \mathrm{~mm}$, and the rock formation was seriously damaged. It can be seen from the drilling monitoring that after the end of the mining at the 222 working face, through the $2 \#$ drilling monitoring, the height of the collapse zone is $17.8 \mathrm{~cm}$, and the height of the water-conducting fractured zone is $64.6 \mathrm{~cm}$; corresponding to the 222 working face of Xiashijie Coal Mine, the rock collapse zone is $71.2 \mathrm{~m}$, and the water-conducting fractured zone is $258.4 \mathrm{~m}$.

Through the direct observation of the physical similar simulation test results and the indirect observation of the internal damage of the overlying rock through the borehole television, in the process of mining in the 3-2\# coal seam
2301 working face, the range and height of the overburden damage continue to increase with the mining of the model. However, affected by the fragmentation and expansion effect of the coal and rock below, the increase in the damage height of the overburden gradually decreases with the increase in the number of pressures. After the end of the mining in the 2301 working face of the 3-2\# coal seam, the rock activity stabilizes. When mining 4-2\# coal seam 222 working face, with the continuous advancement of the working face, the roof of the coal seam sinks so that the upper collapsed rock layer continues to sink and damage to the bottom rock layer. The upper rock layer collapses sequentially due to periodic pressure. After the end of the stoping, a relatively stable squeeze equilibrium structure forms between the broken rock blocks and finally tended to a stable state. Observation from borehole 2\# shows that the cracks have developed to the surface, and the number of cracks has increased significantly. The TV analysis results of the model borehole show that the evolution process of the overburden rupture is "Fracture expansion-Fracture-Collapse."

4.3. Two-Zone Distribution Characteristics. Through the physical similarity simulation test, the heights of the two zones were measured in sequence after the end of the mining at the 2301 working face and the 222 working face, and the distribution maps of the two zones were drawn, as shown in Figures 8 and 9. To facilitate the observation of the failure mode of the rock formation, the fracture line of the rock formation has been added, and the angle measured. It can be seen from Figure 8 that after the end of mining in the 3-2\# coal seam 2301 working face, the caving zone above the 


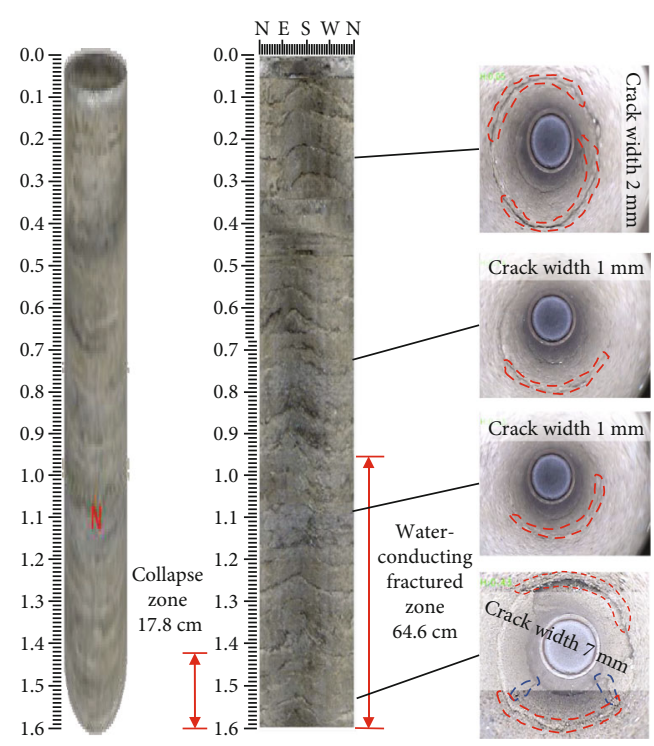

(a) Drilling panoramic fissure peep imaging

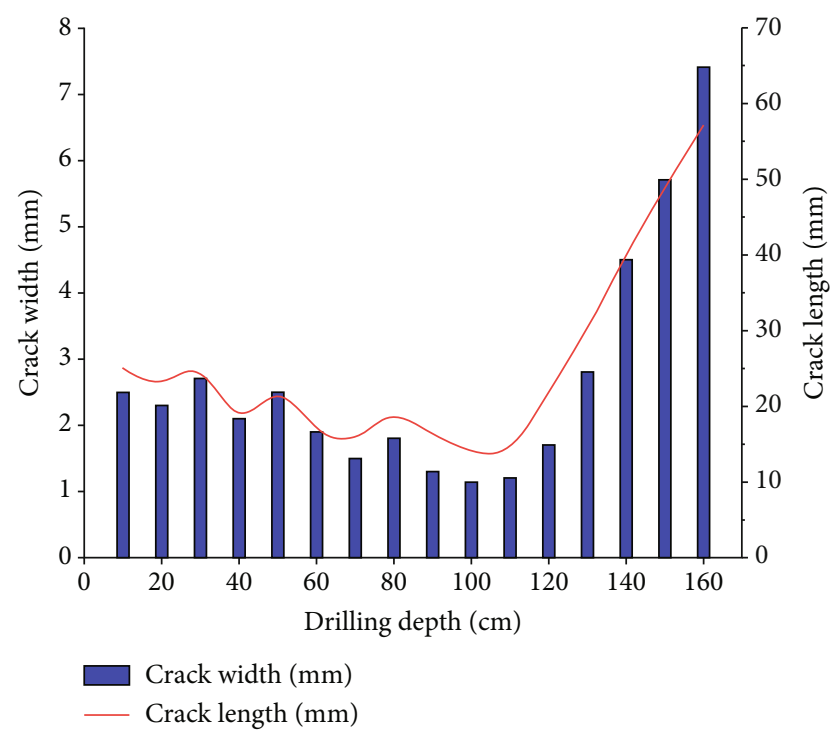

(b) Statistical characteristics of different depth cracks

Figure 7: The imaging and statistical characteristics of the overburden cracks in the 2 \# borehole after the end of mining the 222 working face.

working face is approximately trapezoidal in distribution. The breaking angle on the left side of the goaf is $70^{\circ}$, and the breaking angle on the right side is $68^{\circ}$. Because the coal pillars at the two ends of the working face have a supporting effect on the overlying strata, the displacement and deformation of the middle strata are larger than those on both sides; therefore, the height of the water-conducting fractured zone is slightly higher at both ends of the working face and lower in the middle, showing a "saddle-shaped" distribution.

After the stoping in the 4-2\# coal seam 222 face, the distribution of the two zones is shown in Figure 9. It can be seen from Figure 9 that the mining of 222 working face caused a large-scale collapse of the rock layer between the two coals, and the damaged rock layer of the 3-2\# coal seam continued to be bent and subsided after mining. The breaking angle on the left side of the goaf developed to $81^{\circ}$, and the breaking angle on the right side developed to $74^{\circ}$, increasing by $15.7 \%$ and $8.8 \%$. The development height of the two zones continued to expand upward, and the development of the two zones was like a "saddle shape" until the end of the stoping.

Through borehole television monitoring, the heights of the overlying caving zone and water-conducting fractured zone after the end of mining in the 2301 and 222 working faces are shown in the table of the height of the two zones after the end of the mining in Table 2.

The results show that after the 3-2\# coal seam is mined, the average height of the collapsed zone and the waterconducting fractured zone are $20.2 \mathrm{~m}$ and $150.0 \mathrm{~m}$, and the caving ratio and the cracking ratio are 4.5 and 33.3. After the coal seam group stoping, the collapsed zone and waterconducting fractured zone eventually developed to $70.6 \mathrm{~m}$ and $257.4 \mathrm{~m}$, and the caving ratio and the cracking ratio are 4.87 and 17.75 , increasing by $15.7 \%$ and $8.8 \%$.

According to $\mathrm{Yu}$ and Zhang [26], it is known that when the coal seam inclination angle is $0^{\circ} \sim 54^{\circ}$ in the range of $0^{\circ} \sim 54^{\circ}$, the caving zone height formula (1) and the waterconducting fractured zone height formula (2) are as follows:

$$
\begin{gathered}
H c=\frac{100 \sum M}{2.1 \sum M+16} \pm 2.5, \\
H f=\frac{100 \sum M}{1.2 \sum M+2.0} \pm 8.9 .
\end{gathered}
$$

In which, $\sum M$ is the total thickness of the coal seam, and its cumulative thickness does not exceed $15 \mathrm{~m}$; \pm is the allowable range of error; $H c$ is the height of the collapse zone; $\mathrm{Hf}$ is the height of the fracture zone.

The average thickness of the 3-2\# coal seam in the 2301 working face is $4.5 \mathrm{~m}$, which can be calculated in the above formula (1) and formula (2), and the height of the collapse zone is in the range of $15.2 \mathrm{~m} \sim 20.2 \mathrm{~m}$. The height of the water-conducting fractured zone is in the range of $51.9 \mathrm{~m} \sim 69.7 \mathrm{~m}$. The average thickness of the 4-2\# coal seam in the 222 working face is $10.0 \mathrm{~m}$. After the $4-2 \#$ coal seam is stopped, the cumulative thickness of the coal seam is $14.5 \mathrm{~m}$. Take it into the above formula (1) and formula (2) to calculate that the height of the collapse zone is in the range of $28.7 \mathrm{~m} \sim 33.7 \mathrm{~m}$. The height of the water-conducting fractured zone is in the range of $65.8 \mathrm{~m} \sim 83.6 \mathrm{~m}$. Table 3 shows the formula to calculate the height range of the two zones.

The development height of the two zones calculated by the formula has a large deviation from the development height of the two zones obtained by the physical similarity simulation experiment, which is not enough to support it. Because the coal seam of Xiashijie Coal Mine is buried at $640 \mathrm{~m}$ and belongs to a mine with a strong impact tendency, the development height of the two zones calculated by the conventional theoretical formula is quite different from the value of the physical similarity simulation test. Therefore, in order to verify the accuracy of the borehole TV 


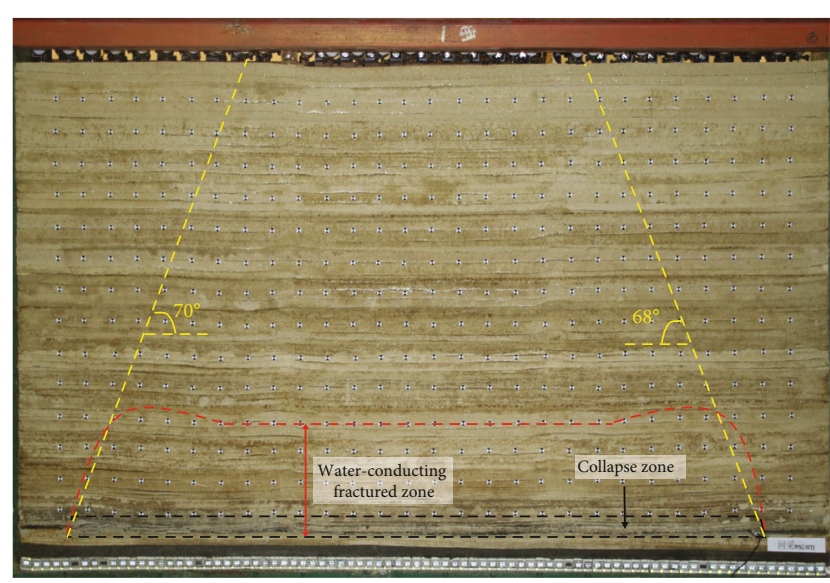

Figure 8: 3-2\# coal seam's two-zone distribution map.

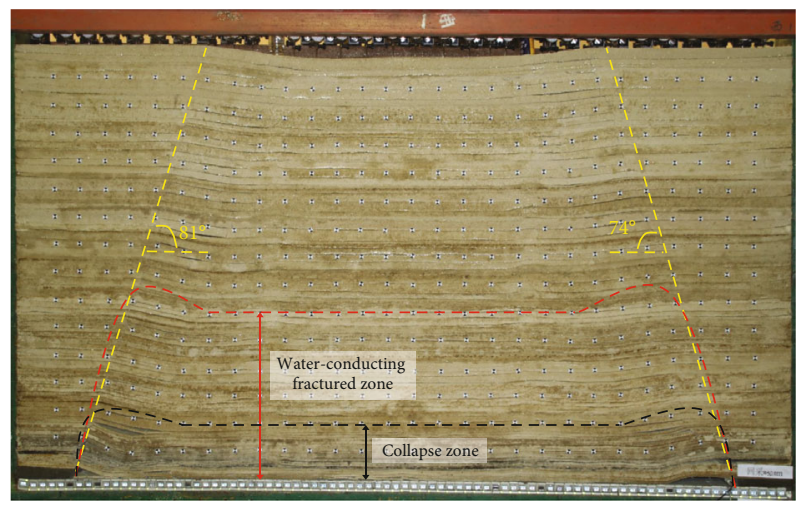

FIgURE 9: 4-2\# coal seam's two-zone distribution map.

monitoring results, acoustic emission energy evolution positioning will be used to further analyze the development height of the two zones.

\subsection{Positioning Analysis of Overburden Energy Evolution.} With the aid of the location of acoustic emission events, the fissure development and the height of the two zones after joint mining of the coal seam group are inverted to verify the accuracy of the height of the two zones monitored by the borehole TV system. According to the size of the event energy, the acoustic emission events are divided into 4 different levels of less than 10,000, 10,000 50,000, and $50,000 \sim 100,000$ and greater than $100,000 \mathrm{mV} \cdot \mu \mathrm{s}$. According to the frequency of the occurrence of acoustic emission events in the overburden and the location of the concentrated energy distribution, the distribution range of the collapse zone and water-conducting fractured zone is drawn.

From Figure 10, the three-dimensional location of the acoustic emission event at the end of mining at 2301 working face shows that after the end of mining in the 3-2\# coal seam 2301 working face, the heights of the collapse zone and the water-conducting fractured zone are $20.8 \mathrm{~m}$ and $150.8 \mathrm{~m}$, respectively, which are $0.6 \mathrm{~m}$ and $0.8 \mathrm{~m}$ apart from the average height of the two zones monitored by the borehole TV system. Due to coal mining, the overlying rock formations with a strong impact tendency are severely broken and dam- aged, so high-energy events are mostly concentrated in the collapse zone. The 3-2\# coal seam is relatively thin. After the end of the mining, the rock in the middle of the model moved, and there were slag drop, loosening, and small cracks between the rock layers, so small energy events were scattered in the middle of the rock. The upper rock layer is less affected by mining disturbance, and the rock layer has no subsidence and cracks, so the acoustic emission monitoring system did not capture the energy event.

From Figure 11, the acoustic emission three-dimensional space positioning map of the 222 working face shows that, after the end of coal mining in the 4-2\# coal seam 222 face, the heights of the collapse zone and the water-conducting fractured zone shown in the upper seismic source envelope of the face are $71.0 \mathrm{~m}$ and $258.0 \mathrm{~m}$; the average height of the two zones differs from the height monitored by the borehole TV by $0.4 \mathrm{~m}$ and $0.6 \mathrm{~m}$. When the $4-2 \#$ coal seam is completed mining, the rock layers among the coal seam groups have collapsed more severely, and the damage forms are obvious. Therefore, within the collapse zone, the largeenergy events are significantly increased and become denser. Due to the collapse of the key layer to form a structure, the central rock layer sinks, and the local fractures are compacted. Therefore, the energy of small events is denser near the water-conducting fractured zone. After the coal seam group was mined, the surface subsided, and small cracks formed, so small energy events were scattered in the upper part of the model.

Acoustic emission monitoring results corroborate the results of borehole TV monitoring. The comprehensive analysis of borehole TV monitoring and acoustic emission monitoring shows that after the combined mining of deep roof coal seams with a strong impact tendency, the average height of the final collapse zone obtained from the physical similarity simulation test is $70.8 \mathrm{~m}$, and the average height of the water-conducting fractured zone is $257.7 \mathrm{~m}$. Through the energy location of the acoustic emission monitoring system, it can be known that large-energy events are mostly concentrated in the collapse zone, and there are more energy events near the contour of the water-conducting fractured zone than in the upper and lower parts. From this, it is known that the energy dissipation of the overburden rupture of the upper strata is "Release-Accumulate-Release," and the $\mathrm{AE}$ monitoring system can provide early warning for coal mine safety production.

\section{Numerical Simulation Verification Analysis}

5.1. Selection of Numerical Simulation Software and Determination of Calculation Parameters. The 3DEC software is currently an ideal numerical simulation software for simulating the movement process of a rock formation after it is broken. It can ideally analyze and study the potential failure modes of rock mass directly related to the discontinuous features. At the same time, it can also simulate the process of roof falling, collapse, and separation after coal seam excavation. A discrete element numerical model is constructed according to the characteristics of the coal and rock layers in the Xiashijie Coal Mine, and the height of 
TABLE 2: The development height table of the two zones after the end of the working face.

\begin{tabular}{|c|c|c|c|c|c|c|}
\hline \multirow[b]{2}{*}{ Working face } & \multicolumn{2}{|c|}{$1 \#$ drilling } & \multicolumn{2}{|c|}{ 2\# drilling } & \multicolumn{2}{|c|}{ Average } \\
\hline & $\begin{array}{c}\text { Height of collapse } \\
\text { zone/m }\end{array}$ & $\begin{array}{l}\text { Height of fissure } \\
\text { zone/m }\end{array}$ & $\begin{array}{l}\text { Height of collapse } \\
\text { zone } / \mathrm{m}\end{array}$ & $\begin{array}{c}\text { Height of fissure } \\
\text { zone } / \mathrm{m}\end{array}$ & $\begin{array}{c}\text { Height of collapse } \\
\text { zone } / \mathrm{m}\end{array}$ & $\begin{array}{l}\text { Height of fissure } \\
\text { zone } / \mathrm{m}\end{array}$ \\
\hline $\begin{array}{l}2301 \text { working } \\
\text { face }\end{array}$ & 19.6 & 149.6 & 20.8 & 150.4 & 20.2 & 70.6 \\
\hline $\begin{array}{l}222 \text { working } \\
\text { face }\end{array}$ & 70.0 & 256.4 & 71.2 & 258.4 & 150.0 & 257.4 \\
\hline
\end{tabular}

TABle 3: Formula calculates the development height range of the two zones.

\begin{tabular}{lcc}
\hline $\begin{array}{l}\text { Working face } \\
\text { stoping situation }\end{array}$ & $\begin{array}{c}\text { Strike model overlying two zones } \\
\text { Height range of } \\
\text { collapse zone/m }\end{array}$ & $\begin{array}{c}\text { Height range of } \\
\text { fissure zone/m }\end{array}$ \\
\hline $\begin{array}{l}\text { 2301 working face } \\
\text { stoping end }\end{array}$ & $15.2 \sim 20.2$ & $51.9 \sim 69.7$ \\
$\begin{array}{l}222 \text { working face } \\
\text { stoping end }\end{array}$ & $28.7 \sim 33.7$ & $65.8 \sim 83.6$ \\
\hline
\end{tabular}

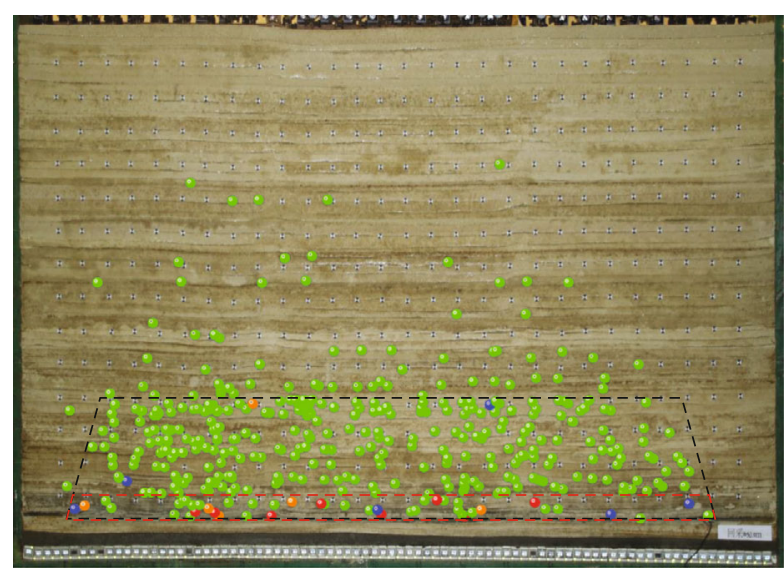

- - . Water-conducting fractured zone range

- - . . Collapse zone range

- $<10000$

- $10000 \sim 50000$

- $50000 \sim 100000$

- $>100000$

FIgURE 10: Three-dimensional location map of acoustic emission event at the end of mining at 2301 working face.

the two zones is comprehensively determined through numerical calculation.

According to the field geological data and rock mechanics test results, the final coal rock mechanics parameters are determined (Table 4) and provide a reliable basis for the numerical simulation calculation.

5.2. Establishment of the Numerical Calculation Model. The geological characteristics of the numerical model of the overburden failure characteristics and the mining sequence of the working face are consistent with the physical similarity simulation experiment, as shown in Figure 12. The model

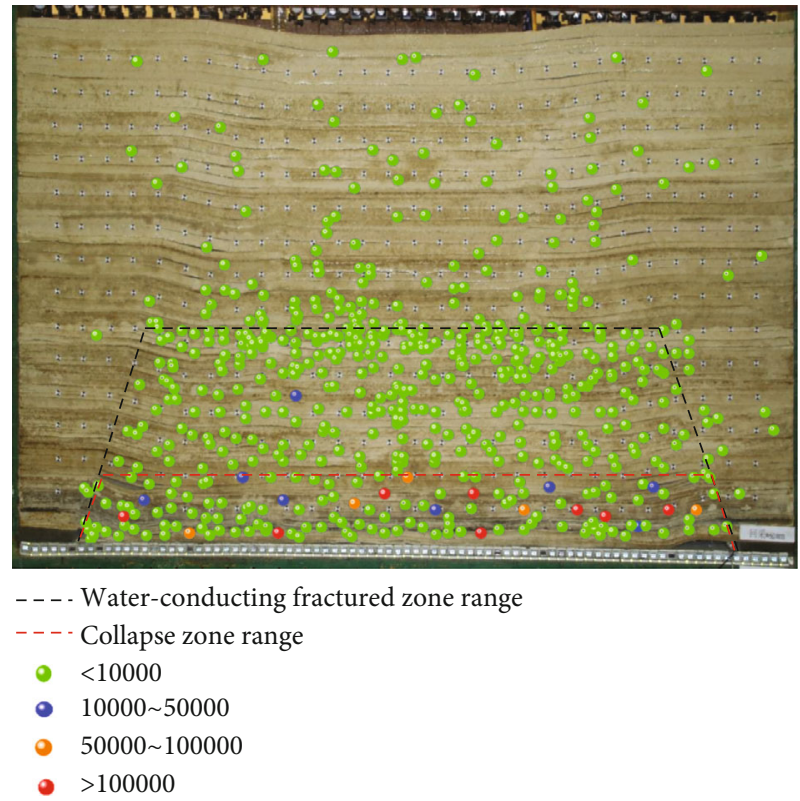

Figure 11: Three-dimensional location map of acoustic emission event at the end of mining at 222 working face.

has a length of $1,200 \mathrm{~m}$, a width of $80 \mathrm{~m}$, and a height of $650 \mathrm{~m}$.

5.3. Numerical Calculation Analysis Results. Figure 13 shows the distribution of overburden cracks in the 3-2\# coal seam at the end of mining. During the advancing process of the 2301 working face, the continuous increase and expansion of cracks cause the rock formation to collapse continuously. Due to the influence of the boundary coal pillars, the overlying strata at both ends of the working face remained in a suspended state after the advancement of the 2301 working face is completed. The caving zone is mainly concentrated in the lower black dotted trapezoidal area with a height of about $18.4 \mathrm{~m}$, the difference between the average height of the collapse zone measured by the similar simulation test BT-AE joint monitoring system of $20.5 \mathrm{~m}$ is $2.1 \mathrm{~m}$, and the deviation is small. The water-conducting fractured zone is mainly concentrated in the red dotted trapezoidal area. The yellow rectangles on both sides are accompanied by the existence of fractures. The height of the water-conducting fractured zone is $147.6 \mathrm{~m}$. Compared with the similar simulation test BT$\mathrm{AE}$ joint monitoring system, the average height of the water-conducting fractured zone measured by $150.4 \mathrm{~m}$ differs by $2.8 \mathrm{~m}$, and the error is small. 
TABLE 4: Main coal and rock mechanical parameters.

\begin{tabular}{|c|c|c|c|c|c|c|c|}
\hline Number & Lithology & $\begin{array}{l}\text { Bulk density } \\
\left(\mathrm{kN} / \mathrm{m}^{3}\right)\end{array}$ & $\begin{array}{l}\text { Tensile strength } \\
(\mathrm{MPa})\end{array}$ & $\begin{array}{l}\text { Elastic modulus } \\
\qquad(\mathrm{GPa})\end{array}$ & $\begin{array}{l}\text { Internal friction } \\
\text { angle }\left(^{\circ}\right)\end{array}$ & $\begin{array}{l}\text { Cohesion } \\
(\mathrm{MPa})\end{array}$ & $\begin{array}{l}\text { Poisson's } \\
\text { ratio }\end{array}$ \\
\hline 1 & $\begin{array}{l}\text { Fine-grained } \\
\text { sandstone }\end{array}$ & 2.21 & 1.56 & 1.415 & 25.48 & 2.40 & 0.17 \\
\hline 2 & Siltstone & 2.45 & 0.78 & 0.885 & 15.3 & 4.90 & 0.23 \\
\hline 3 & Conglomerate & 2.64 & 3.02 & 0.345 & 34.72 & 2.91 & 0.19 \\
\hline 4 & Sandstone & 2.35 & 0.88 & 0.925 & 11.8 & 3.47 & 0.25 \\
\hline 5 & $\begin{array}{l}\text { Medium-grained } \\
\text { sandstone }\end{array}$ & 2.31 & 1.12 & 1.214 & 27.77 & 1.32 & 0.22 \\
\hline 6 & Sandy mudstone & 2.54 & 0.23 & 0.346 & 26.28 & 0.48 & 0.27 \\
\hline 7 & $\begin{array}{l}\text { Coarse-grained } \\
\text { sandstone }\end{array}$ & 2.41 & 0.48 & 0.817 & 30.84 & 1.65 & 0.25 \\
\hline 8 & Mudstone & 2.62 & 0.95 & 1.321 & 27.21 & 1.88 & 0.25 \\
\hline 9 & 3-2\# coal seam & 1.35 & 1.33 & 1.67 & 29.74 & 2.68 & 0.31 \\
\hline 10 & 4-2\# coal seam & 1.45 & 1.86 & 1.84 & 30.87 & 3.61 & 0.21 \\
\hline
\end{tabular}

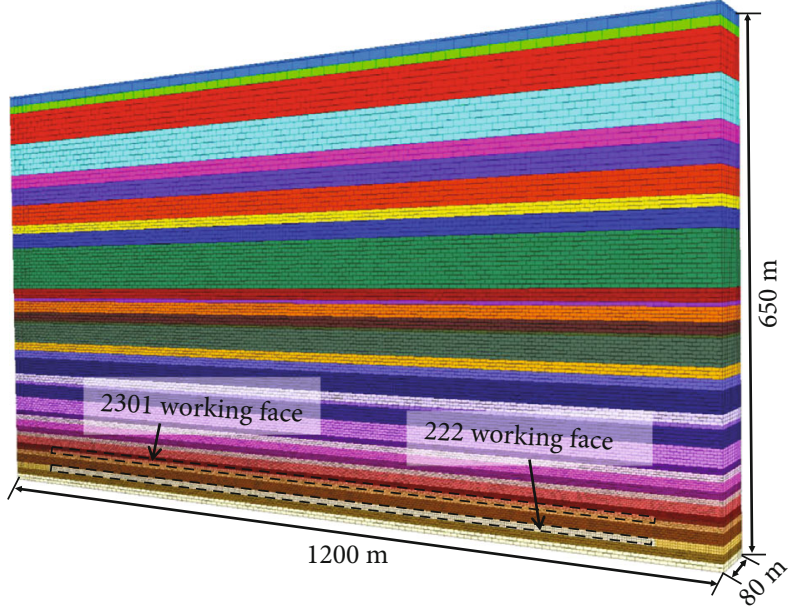

FIGURE 12: 3DEC numerical calculation model.

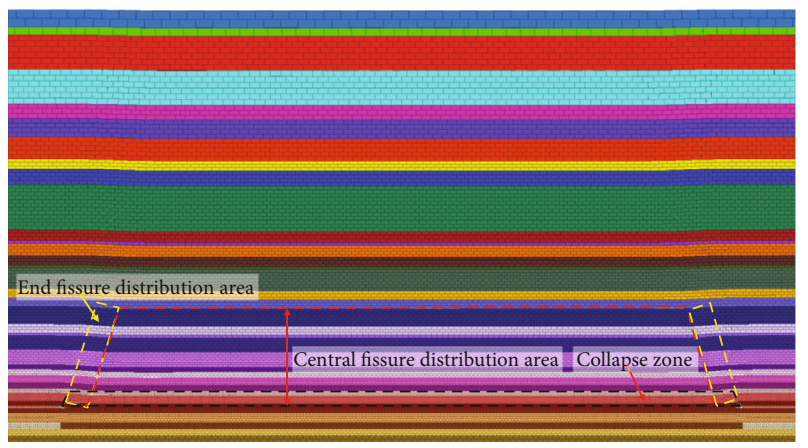

Figure 13: 3-2\# coal seam overburden collapse characteristics at the end of mining.

Figure 14 shows the distribution of overburden cracks in the 4-2\# coal seam after mining. During the advancing process of working face 222, the overlying rock strata are affected by mining disturbances and cause a large number of cracks and separations, causing collapse and subsidence.

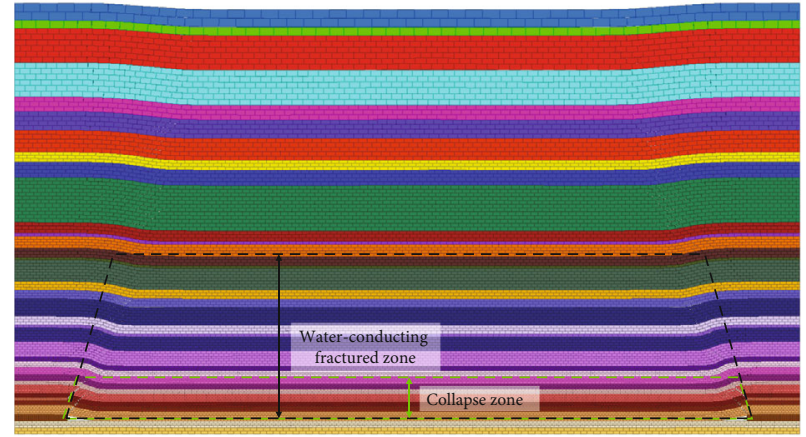

FIgURE 14: 4-2\# coal seam overburden collapse characteristics at the end of mining.

The collapse zone is mainly concentrated in the green trapezoidal range, with a height of about $68.4 \mathrm{~m}$. The difference between the average height of the collapse zone measured by the similar simulation test BT-AE joint monitoring system is $70.8 \mathrm{~m}$ by $2.4 \mathrm{~m}$, and the deviation is small. Serious fracture damage occurs in the rock above the goaf at both ends of the working face, and the fracture cracks are more obvious. The rock layer near the coal roof was damaged to a greater extent, and the cracks are the most concentrated. However, the middle and upper rock layers squeeze and rub against each other after the collapse, and the number of cracks is significantly less than that of the lower rock layers. The crack zone is mainly concentrated in the black trapezoidal area with a height of $252.0 \mathrm{~m}$. Compared with the similar simulation test BT-AE joint monitoring system, the average height of the fissure zone measured by the BT$\mathrm{AE}$ joint monitoring system is different by $5.7 \mathrm{~m}$, and the error is small.

Under the combined mining of coal seams with a strong impact tendency, there is a large error in the height of the two zones of overlying strata through numerical calculation and the height of the caving zone and the water-conducting fractured zone calculated by the empirical formula. The height of the two zones measured by the 3DEC numerical 
analysis is slightly smaller than the height of the two zones obtained by the physical similarity simulation experiment within a reasonable range, which well proves the accuracy of the two zones' height measured by the physical similarity simulation experiment.

\section{Conclusions}

(1) Under the condition of combined mining of the strong flushing coal seam group in the lower stone section, the number of overburden cracks increases with the depth, mostly near the roof. Controlled by the mining stress field in the direction of $115^{\circ}$ west from north to west, the direction of the overburden cracks is mainly concentrated in the area of $300^{\circ}-30^{\circ}$

(2) After the 3-2\# coal seam is mined, the overburden fracture angles are $70^{\circ}$ and $68^{\circ}$, respectively, and the caving ratio and cracking ratio are 4.5 and 33.3. After the coal seam group stoping, the overburden fracture angles eventually developed to $81^{\circ}$ and $74^{\circ}$, increasing by $15.7 \%$ and $8.8 \%$, and the caving ratio and cracking ratio are 4.87 and 17.75 . After the $4-2 \#$ coal seam is mined, due to the fracture of the upper subkey layer, the cracks expand in a wide range, and the height of the cracked zone increases, which increases the proportion of the two zones. TV analysis of boreholes shows that the evolution characteristic course of overburden rupture is "fracture expansion-fracture-collapse"

(3) The AE analysis results show that the "releaseaccumulate-release" energy evolution process of overburden rupture under mining conditions has a phased relationship with fracture expansion, and the energy positioning results are consistent with the BT observation fracture distribution. Moreover, high-energy events are mostly concentrated in the collapse zone, indicating that $\mathrm{AE}$ has the practicality of disaster warning. When the coal seam is buried deep and has a tendency to impact, the height values of the two zones calculated by the empirical formula differ greatly from the actual height. To ensure the smooth progress of water-preserving mining, physical similarity simulation tests should be conducted reasonably through the BT-AE system joint monitoring and verified through discrete element numerical calculations to comprehensively determine the height of the water-conducting fractured zone. Formulate appropriate water prevention and control plans and programs to solve the problems of the development height of the two zones of the strong impact tendency roof and the prevention and control of water in the close coal seam group of Xiashijie Coal Mine

\section{Data Availability}

The test data used to support the findings of this study are included in the article. Readers can obtain data supporting the research results from the test data table in the paper.

\section{Conflicts of Interest}

No conflict of interest exists in the submission of this manuscript.

\section{Authors' Contributions}

The manuscript is approved by all authors for publication. All the authors listed have approved the manuscript that is enclosed.

\section{Acknowledgments}

This work is sponsored by the National Nature Science Foundation of China (Nos. 51904227 and 52004201) and the Shaanxi Natural Science Fundamental Research Program Enterprise United Fund (2019JLZ-04).

\section{References}

[1] H. P. Xie, L. X. Wu, and D. Z. Zheng, "Prediction on the energy consumption and coal demand of China in 2025," Journal of China Coal Society, vol. 44, no. 7, pp. 1949-1960, 2019.

[2] L. M. Fan, "Discussing on coal mining under water-containing condition," Coal Geology \& Exploration, vol. 33, no. 5, pp. 5356, 2005.

[3] Y. G. Wang, W. B. Guo, and E. H. Bai, "Characteristics and mechanism of overlying strata movement due to highintensity mining," Journal of China Coal Society, vol. 43, no. S1, pp. 28-35, 2018.

[4] C. H. Zhao, D. W. Jin, and Z. X. Li, "Analysis of overlying aquifer water inrush under mining the Topmineable seam in Yushen Mining Area," Journal of China Coal Society, vol. 46, no. 2, pp. 523-533, 2021.

[5] X. P. Lai, F. Cui, and J. T. Cao, "Analysis on characteristics of overlying rock caving and fissure conductive water in top-coal caving working face at three soft coal seam," Journal of China Coal Society, vol. 42, no. 1, pp. 148-154, 2017.

[6] J. Q. Wang, M. Y. Lu, and Q. X. Wang, "Study on ecological environment assessment of water conservation mining based on entropy weight method and cloud model," Coal Science and Technology, pp. 1-8, 2020.

[7] S. M. Wang, Q. X. Huang, and L. M. Fan, "Study on overburden aquclude and water protection mining regionazation in the ecological fragile mining area," Journal of China Coal Society, vol. 35, no. 1, pp. 7-14, 2010.

[8] W. B. Guo, E. H. Bai, and G. B. Zhao, "Current status and progress on overburden and surface damage and prevention technology of high-intensity mining," Journal of China Coal Society, vol. 45, no. 2, pp. 509-523, 2020.

[9] X. Cheng, G. M. Zhao, and Y. M. Li, "Evolution of overburden mining-induced fractured zone and pressure-relief gas drainage in soft rock protective seam," Journal of Mining \& Safety Engineering, vol. 37, no. 3, pp. 533-542, 2020.

[10] Y. Xue, J. Liu, P. G. Ranjith, X. Liang, and S. H. Wang, "Investigation of the influence of gas fracturing on fracturing characteristics of coal mass and gas extraction efficiency based on a multi-physical field model," Journal of Petroleum Science and Engineering, vol. 206, article 109018, 2021.

[11] D. M. Yang, W. B. Guo, and G. B. Zhao, "Height of waterconducting zone in longwall top-coal caving mining under 
thick alluvium and soft overburden," Journal of China Coal Society, vol. 44, no. 11, pp. 3308-3316, 2019.

[12] X. Z. Wang, J. L. Xu, and H. K. Han, "Stepped development characteristic of water flowing fracture height with variation of mining thickness," Journal of China Coal Society, vol. 44, no. 12, pp. 3740-3749, 2019.

[13] B. C. Zhao, Z. R. Liu, and C. Tong, "Relation between height of water flowing fractured zone and mining parameters," Journal of Mining \& Safety Engineering, vol. 32, no. 4, pp. 634-638, 2015.

[14] J. G. Liu and L. T. Zhao, "Theory of water protection and practice application in mining based on the backfilling mining technology," Journal of China Coal Society, vol. 39, no. 8, pp. 1545-1551, 2014.

[15] Q. X. H. J. Cao and J. W. Du, "Research on three-field evolution and rational coal pillar staggered distance in shallow buried closely spaced multi-seam mining," Journal of China Coal Society, vol. 44, no. 3, pp. 681-689, 2019.

[16] X. K. Yang, X. M. Zhang, and Z. J. Hou, "Numerical simulation of safety mining under a river in Yushuwan coal mine," Journal of Mining \& Safety Engineering, vol. 25, no. 3, pp. 305308, 2008.

[17] Z. L. Fan and Z. G. Liu, "Mud cover effect of mining-induced failure of soft overburden in thick clay strata," Journal of Mining \& Safety Engineering, vol. 37, no. 6, pp. 1196-1204, 2020.

[18] F. Q. Wu, J. Y. Liu, T. Liu, H. Zhuang, and C. Yan, “A method for assessment of excavation damaged zone (EDZ) of a rock mass and its application to a dam foundation case," Engineering Geology, vol. 104, no. 3-4, pp. 254-262, 2009.

[19] S. N. Dong, Z. B. Yang, and Z. K. Ji, "Study on water-preserved mining technology of burnt rock aquifer beside the large reservoir in Shenfu mining area," Journal of China Coal Society, vol. 44, no. 3, pp. 709-717, 2019.

[20] X. M. Guo and S. N. Dong, "Seepage law of bedrock aquifer and water-preserved mining technology in deep coal seam mining," Journal of China Coal Society, vol. 44, no. 3, pp. 805-812, 2019.

[21] X. J. Du, G. R. Feng, and T. Y. Qi, "Roof stability analyses of "water-preserved and water-stored" coal mining with constructional backfill mining," Journal of China Coal Society, vol. 44, no. 3, pp. 821-830, 2019.

[22] X. P. Lai, M. F. Cai, F. H. Ren, M. Xie, and T. Esaki, “Assessment of rock mass characteristics and the excavation disturbed zone in the Lingxin Coal Mine beneath the Xitian river, China," International Journal of Rock Mechanics \& Mining Sciences, vol. 43, no. 4, pp. 572-581, 2006.

[23] X. P. Lai, H. C. Xu, J. D. Fan et al., "Study on the mechanism and control of rock burst of coal pillar under complex conditions," Geofluids, vol. 2020, Article ID 8847003, 19 pages, 2020.

[24] X. P. Lai, J. J. Dai, and C. Li, "Analysis on hazard characteristics of overburden structure in steeply inclined coal seam," Journal of China Coal Society, vol. 45, no. 1, pp. 122-130, 2020.

[25] X. P. Lai, J. J. Dai, H. D. Xu, and X. Z. Chen, "Multifield environmental analysis and hazards prevention of steeply inclined deep coal mining," Advances in Civil Engineering, vol. 2021, Article ID 6651088, 12 pages, 2021.

[26] X. Y. Yu and E. Q. Zhang, Mining Damage Science, Coal Industry Press, Beijing, China, 2nd ed edition, 2010. 